\title{
Effective Management of Parking Area
}

\author{
Suguna M, Shobana G, Mohana Priya P, Kishore R
}

\begin{abstract}
When a car enters the parking area, it takes so much time to find the free slot to park. On the other hand, all the paid parking area owners suffer from handling congestion inside the parking area. They are spending huge amount as a salary for their employees to manage the parking area. So there is huge need for effective management of parking area.So the proposed system describe a method to automate the management of car parking area without manual traffic workers i.e., it discusses a project which presents a miniature model of an automated car parking system that can regulate and manage the number of cars that can be parked in a given space at any given time based on the availability of parking slot. By using the logic which is given in the database the parking space is effectively managed. This proposed system is suitable for implementing in all paid parking areas such as in malls, hospitals, etc.,
\end{abstract}

Keywords: congestion; reducing the manpower; parking slot allocation; image processing.

\section{INTRODUCTION}

The parking place is very important all over the world especially in the cities. Every day thousands of car drivers spend a lot of the time to find where to park.

The result of this situation is theft in urban areas, increasing traffic congestion and frustration of drivers.

Human errors are the major source for traffic accidents, therefore building in-car technologies for checking the parking lot, avoiding accidents and guidance to the parking facility is turning out to be an integral area for research nowa-days.[1]

The objective of such technologies is the reduction of the burden on driver, improvement of the parking capacity, and provision of reliable and secure parking management.

The parking meters which rely on coins or tokens is an inefficient system as it requires man power for management of the parking and exact change for paying the parking charges. Parking control and enforcement systems provide efficient and effective monitoring of meter and it also keeps a check on any violations of the parking lot.[3] This results in best possible use of the parking space for increasing the revenue. However, it requires man power which needs some capital. Currently used parking system is not an efficient one; as the drivers are allowed to park without any restriction and the parking facility cannot be used to its full extent.

Revised Manuscript Received on 14 August, 2019.

Suguna.M, Assistant Professor II, Department of CSE, Kumaraguru College of Technology, Coimbatore, Tamilnadu, India.(Email: Suguna.m.cse@kct.ac.in)

Shobana.G, Assistant Professor II, Department of CSE, Kumaraguru College of Technology, Coimbatore, Tamilnadu, India.(Email: shobana.g.cse@kct.ac.in)

MohanaPriya.P, UG student, Department of CSE, Kumaraguru College of Technology, Coimbatore, Tamilnadu, India.(Email: mohana.16cs@kct.ac.com)

Kishore.R, UG student, Department of CSE, Kumaraguru College of Technology, Coimbatore, Tamilnadu, India.(Email: kishore1.16cs@kct.ac.com).
On a survey, $47 \%$ of people suffer from finding parking slot in malls. They are spending an average time of about 20 minutes to find the empty slot. It result in waste of time, waste of patrol or diesel, frustration etc.,

Now a days automation rules everywhere. The main need of automation is to reduce the amount spend in labor. When the parking area is managed automatically, it reduce the man power to great extent. Due to the trending of cashless payments, everybody following online transactions. So if a system developed with automation and cashless payment, then it will sustain for the future development.[2]

In order to solve this problem, the implementation of automatic traffic car parking is designed for managing parking places is mandatory. It will manage the parking space through image processing technique and the resulting vehicle number is stored and it can be retrieved through the database for entry and exit of the parking and payment for parking of the vehicles.

\section{II.RELATED WORKS}

Before entering into our proposed work, previously existing system and their disadvantage have been discussed below:

\section{A. Tools for indicating the empty parking slot: \\ 1. Sign boards:}

In this method, the available parking slot is denoted by the signboards. Usually, labors are used to manage the signboards. When a slot becomes free, one of the workers in that parking area is needed to take the signboard to place it in that free slot.
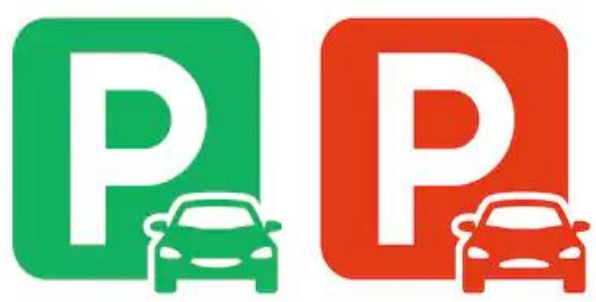

Fig. 1. Sign boards for indicating parking slot

\section{Helium balloon:}

An oil company in South Korea recently design a new method to indicate the free parking slot. This reduces parking search time to a great extent. The helium balloons with the words HERE are placed to indicate exactly where free slots are.[5] These balloons went down when a car is parked and again floats high when the car in that parking slot leaves.

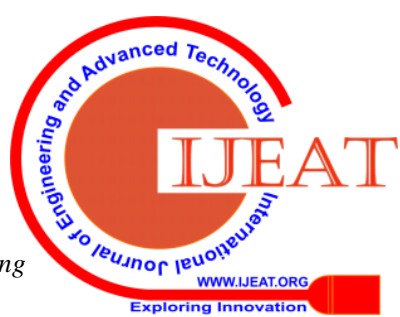




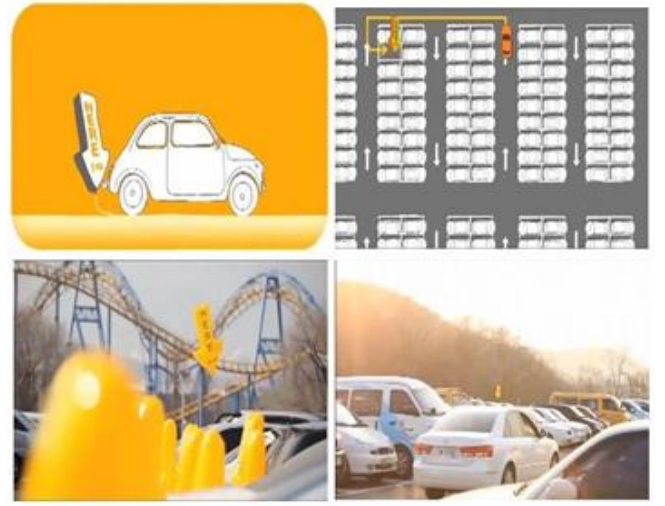

Fig. 2a. Helium balloons usage in parking area

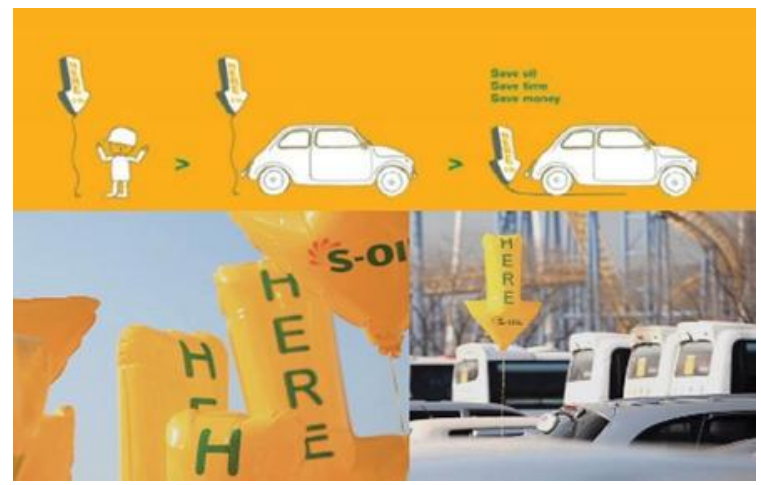

Fig. 2b. Helium balloons usage in parking area

A. In time and out time calculation:

In most of the parking area, in and out time is manually entered by the labor who is working in the parking area. It's a time taking process to enter and allow the car inside the parking area.

\section{III.EFFECTIVE PARKING AREA MANAGEMENT\& RESULTS}

All the existing system needs more manpower to manage the parking area. This makes the owner spend more money on labor's salary. Hence our proposed system is made completely automatic to overcome from all those existing issues. Our system consists of four modules to manage the

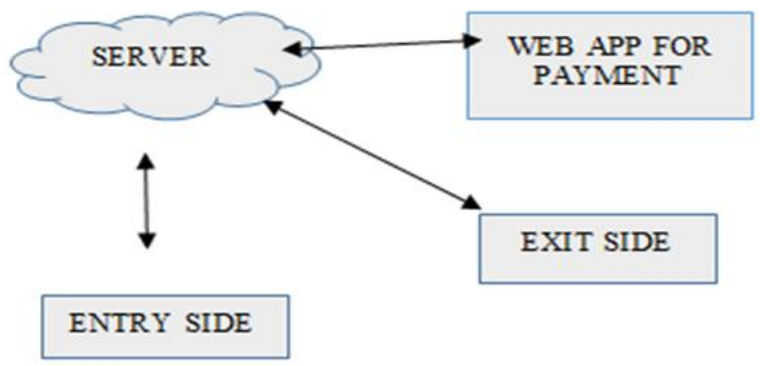

Fig. 1. Block diagram for the proposed system

\section{A. Entry side:}

In the entry side, the number of the car is identified by image processing and its entry is entered in the database along with it's in time. Simultaneously, a parking slot is allocated to that particular car based on the logic applied in the database.

B. Server: entire parking system.

In the server, the database is maintained to manage the parking slot and to record the details of the car which were entered in the parking area. Parking slots are allocated in sequential order. When a car enters, a slot is allocated to that car and its status is updated to allocated state. When a car leaves, the particular slot allocated to that car will be updated to an empty state. Also when a car checks out corresponding out time is noted and payment is calculated based on that timing.

\section{Web app for payment:}

TheQR code is pasted in the entire parking system. When it is scanned, it will redirect to a payment page which prompts to enter the vehicle number. It shows the details of the car such as In time, allotted slot and when check out button is clicked, out time is automatically noted and payment calculation is made based on that out time. Once the payment is successful, the car is granted to leave the parking area. Payment status will also be updated in the database.

\section{Exit side:}

Similar to the entry side, the exit side also detects the car number based on the image processing. Once it is detected, its payment status is verified with the database. When the payment for that car is completed then only the gate will be open to allow the car to leave. Once the car leaves the parking area, the slot allocated to that particular car is updated to empty state in the database.

\section{IV.CONCLUSION}

This paper discusses the importance of automatic car parking system. This innovation includes all the essential advanced featured which are not introduced in the recent trends which helps the people to park the car in the allocated space and resulting in and out time calculations are noted in the back end with the help of database which is the most classy technique used in our innovation. Definitely by using our innovated automatic car parking management system, we can avoid traffic congestion, frustration of driver, reduce time complexity and space complexity.

\section{REFERENCES}

1. J. Dongiiu Geng, Yue Suo, Yu Chen, Jun Wen, Yongqing $\mathrm{Lu}$, Remote Access and Control System Based on Android Mobil Phone, vol.2. Journal of Computer Applications, 2011, pp. 560-562

2. M. Fengsheng Yang, Android Application Development Revelation, China Machine Press, 2010

3. M.A.R. Sarkar, A.A. Rokoni, M.O. Reza, M.F. Ismail, "Smart Parking system with image processing facility", I.J. Intelligent Systems and Applications, 2012, vol. 3, pp. 41-47.

4. Z. L. Wang, C. H. Yang, and T. Y. Guo, "The design of an autonomous parallel parking neuro-fuzzy controller for a car-like mobile robot," in Proceedings of the SICE Annual Conference, Taipei, 2010, pp. 2593-2599.

5. http://freakonomics.com/2013/08/16/how-to-save-timehunting-for-a-parking-spot-south-korea-edition/. 